University of Nebraska - Lincoln

DigitalCommons@University of Nebraska - Lincoln

USDA Forest Service / UNL Faculty Publications U.S. Department of Agriculture: Forest Service -National Agroforestry Center

2007

\title{
Postfire soil burn severity mapping with hyperspectral image unmixing
}

\author{
Pete Robichaud \\ USFS Rocky Mountain Research Station, probichaud@fs.fed.us \\ Sarah A. Lewis \\ Rocky Mountain Research Station, sarahlewis@fs.fed.us \\ Denise Y.M. Laes \\ Remote Sensing Applications Center \\ Andrew T. Hudak \\ Rocky Mountain Research Station, ahudak@fs.fed.us \\ Raymond F. Kokaly \\ US Department of the Interior Geological Survey \\ See next page for additional authors
}

Follow this and additional works at: https://digitalcommons.unl.edu/usdafsfacpub

Robichaud, Pete; Lewis, Sarah A.; Laes, Denise Y.M.; Hudak, Andrew T.; Kokaly, Raymond F.; and Zamudio, Joseph A., "Postfire soil burn severity mapping with hyperspectral image unmixing" (2007). USDA Forest Service / UNL Faculty Publications. 209.

https://digitalcommons.unl.edu/usdafsfacpub/209

This Article is brought to you for free and open access by the U.S. Department of Agriculture: Forest Service -National Agroforestry Center at DigitalCommons@University of Nebraska - Lincoln. It has been accepted for inclusion in USDA Forest Service / UNL Faculty Publications by an authorized administrator of DigitalCommons@University of Nebraska - Lincoln. 


\section{Authors}

Pete Robichaud, Sarah A. Lewis, Denise Y.M. Laes, Andrew T. Hudak, Raymond F. Kokaly, and Joseph A. Zamudio 


\title{
Postfire soil burn severity mapping with hyperspectral image unmixing
}

\author{
Peter R. Robichaud ${ }^{\text {a }}$, Sarah A. Lewis ${ }^{a, *}$, Denise Y.M. Laes ${ }^{\text {b }}$, Andrew T. Hudak ${ }^{\text {a }}$, \\ Raymond F. Kokaly ${ }^{c}$, Joseph A. Zamudio ${ }^{d}$ \\ ${ }^{a}$ Rocky Mountain Research Station, US Department of Agriculture Forest Service, Moscow, Idaho, USA \\ ${ }^{\mathrm{b}}$ Remote Sensing Applications Center, US Department of Agriculture Forest Service, Salt Lake City, Utah, USA \\ ' Spectroscopy Laboratory, US Department of the Interior Geological Survey, Denver, Colorado, USA \\ d Applied Spectral Imaging, Boulder, Colorado, USA
}

Received 15 August 2006; received in revised form 25 November 2006; accepted 26 November 2006

\begin{abstract}
Burn severity is mapped after wildfires to evaluate immediate and long-term fire effects on the landscape. Remotely sensed hyperspectral imagery has the potential to provide important information about fine-scale ground cover components that are indicative of burn severity after large wildland fires. Airborne hyperspectral imagery and ground data were collected after the 2002 Hayman Fire in Colorado to assess the application of high resolution imagery for burn severity mapping and to compare it to standard burn severity mapping methods. Mixture Tuned Matched Filtering (MTMF), a partial spectral unmixing algorithm, was used to identify the spectral abundance of ash, soil, and scorched and green vegetation in the burned area. The overall performance of the MTMF for predicting the ground cover components was satisfactory $\left(r^{2}=0.21\right.$ to 0.48 ) based on a comparison to fractional ash, soil, and vegetation cover measured on ground validation plots. The relationship between Landsatderived differenced Normalized Burn Ratio (dNBR) values and the ground data was also evaluated $\left(r^{2}=0.20\right.$ to 0.58$)$ and found to be comparable to the MTMF. However, the quantitative information provided by the fine-scale hyperspectral imagery makes it possible to more accurately assess the effects of the fire on the soil surface by identifying discrete ground cover characteristics. These surface effects, especially soil and ash cover and the lack of any remaining vegetative cover, directly relate to potential postfire watershed response processes.
\end{abstract}

(C) 2006 Elsevier Inc. All rights reserved.

Keywords: Hayman Fire; Ash; Mixture tuned matched filter; Hyperspectral; Burn severity

\section{Introduction}

\subsection{Justification}

Burn severity is a broad term used to describe the magnitude of fire effects on vegetation and soil and related ecological processes (Lentile et al., 2006). The severity of a wildland fire is mapped as soon as possible to capture immediate postfire conditions and to assist rapid response rehabilitation crews in mitigating immediate and long-term fire effects on the landscape. Burn severity and recovery potential vary depending upon the pre-fire environment and the intensity and duration of

\footnotetext{
* Corresponding author. Rocky Mountain Research Station, 1221 South Main St., Moscow, ID 83843, USA. Tel.: +1 208883 2346; fax: +1 2088832318. E-mail address: sarahlewis@fs.fed.us (S.A. Lewis).
}

the fire in a given location (DeBano et al., 1998; Ice et al., 2004; Ryan, 2002; Ryan \& Noste, 1983; van Wagtendonk et al., 2004). Although a continuum of fire effects on the environment can be evaluated to assess burn severity (Jain et al., 2004), it is generally mapped in discrete categories of unburned, low, moderate, and high, corresponding to the relative magnitude of change in the post-wildfire appearance of vegetation, litter, and soil (Lutes et al., 2006; Miller and Yool, 2002).

Potential watershed responses to wildland fire, such as increased peak flows, runoff, and erosion, typically increase with severity of fire effects on the ground-surface (DeBano, 2000; Moody \& Martin, 2001; Moody et al., 2005; Robichaud, 2000). Areas that exhibit characteristics of moderate or high soil burn severity, such as soil charring (gray to orange soil color) and complete loss of vegetative cover, are at increased risk of soil erosion. Postfire assessment and mapping of soil burn severity and soil exposure is crucial for making decisions concerning 
erosion mitigation and hillslope stabilization treatments (Lewis et al., 2006; Parsons, 2003).

The goal of this study was to determine how remotely sensed hyperspectral data can be used to analyze and map postfire soil burn severity. The specific objectives were to: 1) use spectral mixture analysis of hyperspectral imagery to discriminate ground characteristics that are indicative of soil burn severity; 2) compare ground measurements to the relative abundance of each endmember estimated from the spectral mixture analysis; and 3) compare spectral mixture analysis results of the burned area with a standard burn severity map derived from multispectral imagery.

\subsection{Traditional burn severity mapping}

Burn severity maps are typically created from multispectral satellite imagery such as Landsat Thematic Mapper (TM) or Enhanced Thematic Mapper Plus (ETM+) (Clark et al., 2003; Orlemann et al., 2002; RSAC, 2005). TM and ETM+ are often used because transformed reflectance $(R)$ values of two bands, near-infrared (NIR; band 4: 750-900 nm) and mid-infrared (MIR; band 7: 2090-2350 $\mathrm{nm}$ ), are particularly sensitive to fireinduced changes in vegetation and soil (Lutes et al., 2006; van Wagtendonk et al., 2004). A decrease in green vegetation and vegetation moisture, due either to fire or to vegetative productivity, causes R4 to decrease with burn severity, while R7 increases because of the decrease in moisture and increased exposure of soil and rock and fewer shadows from trees (Lutes et al., 2006). Therefore, the normalized ratio of these bands, known as the Normalized Burn Ratio (NBR), is used as an index of burn severity (Lutes et al., 2006). The NBR is calculated by:

$\mathrm{NBR}=(\mathrm{R} 4-\mathrm{R} 7) /(\mathrm{R} 7+\mathrm{R} 4)$.

Because the change in vegetation and soil properties due to the fire is a more appropriate measure of fire effects than simply the postfire surface condition, pre- and postfire NBR values are commonly differenced:

$\Delta \mathrm{NBR}=\mathrm{NBR}_{\text {pre }}-\mathrm{NBR}_{\text {post }}$

with the resulting index known as the differenced Normalized Burn Ratio (dNBR) (Lutes et al., 2006). NBR values are strongly positive when vegetation is green and thriving. When vegetation is sparse or senesced, NBR values are near zero; when soil exposure is high and there is little or no green vegetation (such as after a recent fire), NBR values are negative (Lutes et al., 2006). dNBR is also driven by green vegetation and soil exposure, at either end of the burn severity spectrum, but since the pre- and postfire values are differenced, low dNBR values indicate low burn severity and high dNBR values indicate high burn severity (opposite of NBR).

Higher dNBR values are indicative of areas that experienced the greatest change due to the fire, or high burn severity. High burn severity generally indicates some or all of the following: an increase of scorched and blackened vegetation and a decrease in green vegetation, a decrease in vegetative and soil moisture, and increased exposure of light-colored soil and ash (Lutes et al.,
2006). Unburned and areas burned at low severity are indicated by little change from pre-fire conditions, with only light or fine fuels being consumed and minimal increase in soil exposure.

The dNBR is calculated using an immediate postfire image for an initial assessment, and may be repeated one or more years later for an extended assessment. The initial assessment quickly provides a map of the fire perimeter and a preliminary estimate of burn severity to be used for stabilization and rehabilitation planning. However, the initial assessment may not capture the actual severity of the fire, which is evidenced by delayed tree mortality and revegetation. An extended assessment gives a better evaluation of the long-term ecological consequences, which are evaluated from the vegetation recovery and the rate of return to pre-fire conditions - a process that can take up to 10 years or more. One difficulty of extended assessment is the need to calibrate observed responses to pre-fire conditions which may become more difficult in subsequent years (Lutes et al., 2006).

Few studies have assessed the quantitative, physical characteristics of dNBR classes on the ground (Roy et al., 2006). The dNBR has primarily been evaluated through comparisons to the Composite Burn Index (CBI), an index of burn severity assessed in the field across a matrix of vegetative criteria to validate the dNBR (Lutes et al., 2006). The dNBR has been compared to CBI plots with reasonable agreement (Cocke et al., 2005; Epting et al., 2005; Sorbel \& Allen, 2005; van Wagtendonk et al., 2004). Drawbacks of the dNBR and the CBI are that both are qualitative indices which are prone to subjectivity when they are stratified into burn severity classes (Lentile et al., 2006). Another drawback of the CBI is that it requires knowledge of the pre-fire conditions as all values are assigned based on the change in condition due to the fire. Hence, the CBI and dNBR are most accurately assessing the magnitude of change, rather than the current conditions on the ground.

Burned Area Reflectance Classification (BARC) maps are created from classified dNBR values as soon as possible after a fire (Lutes et al., 2006; RSAC, 2005). Valuable time and resources are spent by postfire assessment teams adjusting preliminary BARC maps to produce an acceptable burn severity map related to surface/soil conditions or vegetation mortality (Clark et al., 2003; Hardwick et al., 1997; Hudak et al., 2004; Parsons \& Orlemann, 2002; Patterson \& Yool, 1998). BARC maps require adjustment because the standard formula that is used to classify dNBR values does not universally apply to every vegetation type that burns. For example, in grasslands or areas of sparse pre-fire vegetation, such as chaparral, complete vegetation combustion does not necessarily indicate high burn severity as it would in a forest environment. The adjusted BARC map classes must represent the magnitude of change from pre-fire conditions. Modifications regarding specific resources at risk help direct the interpretation of the burn severity map. To accurately prescribe soil stabilization treatments to high erosion-risk areas, a burn severity map must represent fire effects on the soil surface (Parsons, 2003).

Hyperspectral sensors collect high spectral and spatial resolution data that can distinguish finer surface features than broadband satellite imagery and may be able to better distinguish postfire ground cover and conditions. Jia et al. 
(2006) successfully mapped fractional cover of photosynthetic and non-photosynthetic vegetation and soils using AVIRIS (Airborne Visible and Infrared Imaging Spectrometer) data on the Colorado Front Range. van Wagtendonk et al. (2004) calculated a multi-temporal band ratio similar to dNBR using AVIRIS hyperspectral bands (788 nm and $2370 \mathrm{~nm}$ ), which showed that the ratio between higher spectral resolution data may have the potential to be slightly more sensitive to fire effects than traditional broadband ratios. Their work illustrated the potential advantages of higher spectral resolution and suggested exploiting the discriminatory power of hyperspectral imagery for postfire assessment.

Other methods and sensors have been used to map and classify burn severity. Landmann (2003) used a spectral mixture model with Landsat data to map ash and combustion completeness. His results showed that ash abundance increased with increasing vegetation combustion. Smith et al. (2005) used a spectral mixture model in an African savannah to determine the correlation between increased reflectance (due to the increase in white ash) and burn severity. They found that when the soil was covered with ash, the reflectance in high severity areas was much higher after the fire. Trigg and Flasse (2000, 2001) evaluated the ability of visible through long wavelength mid-infrared reflectance to detect fires and fire effects. They determined that MODIS and Landsat satellite sensors are appropriate for detecting and evaluating the effects of fire in burned shrub-savannah. Others have made remote assessments of burn severity using Landsat, SPOT, and AVIRIS data, many of which are summarized in Lentile et al. (2006).

\subsection{Hyperspectral remote sensing}

Airborne hyperspectral sensors provide imagery in narrow bands of reflectance spectra arranged contiguously from the visible through the short-wave infrared (SWIR) range of the electromagnetic (EM) spectrum, approximately $400 \mathrm{~nm}$ to $2500 \mathrm{~nm}$. The spectral bandwidth and sampling interval typically ranges $10 \mathrm{~nm}$ to $20 \mathrm{~nm}$ and the pixel size of the high spatial resolution images is as fine as $1 \mathrm{~m}$ to $5 \mathrm{~m}$, over an area of many square kilometers. Field spectrometers provide even higher spectral resolution (1-2 nm bandwidths and submeter spatial sampling) for the same spectral range, and can be used to relate the reflectance from ground-surface features to remotely sensed imagery (Clark et al., 2002).

A single image pixel is assumed to be a mixture of the sum of the individual reflectance spectra (endmembers) of the reflective surface materials (Adams et al., 1985; Roberts et al., 1993; Smith et al., 1990). Each pixel retains the characteristic features of the individual spectra from each of the component reflective materials; however, they may be influenced by surrounding pixels (Townshend et al., 2000). Once endmember spectra are identified, spectral unmixing of individual pixels can estimate the fractional component spectra and, in turn, the physical fractional component of the materials within the pixels (Adams et al., 1985; Roberts et al., 1993; Theseira et al., 2003). Recent research has suggested that most rural land cover scenes can be mapped as endmember combinations of green vegetation, non- photosynthetic vegetation, soil and rock, and shade (Adams et al., 1995; Roberts et al., 1993; Theseira et al., 2003). A combination of these endmembers with ash and charred vegetation endmembers would account for the majority of the cover types in a typical postfire scene.

Mixture Tuned Matched Filtering (MTMF) is a type of spectral mixture analysis that performs a 'partial' spectral unmixing by identifying only a single, user-defined endmember at a time (Boardman, 1998). The response of the endmember of interest is maximized and the unknown background is suppressed (Harsanyi \& Chang, 1994). The result is similar to traditional spectral mixture analysis in that grayscale images (scale $0-1$, where 1 is a perfect match) of the endmember of interest are produced. The advantage of this technique is that it is unnecessary to identify all possible endmembers in a scene, and it may be superior for vegetation mapping (Boardman et al., 1995; Glenn et al., 2005; Harris et al., 2006; Mundt et al., 2005; Williams \& Hunt, 2002). MTMF may also outperform standard mixture modeling in the case of subtle, subpixel occurrences (Boardman, 1998), which is often the case after a fire, e.g., small litter or ash fractions. Dominant spectral signatures, such as exposed soil or charred blackness after a fire, make it difficult to discern minor vegetation fractions in an image (Smith et al., 1990). The ability to distinguish even small patches of remaining vegetation or patches of ash would provide a better indication of fire effects on soil.

\section{Study area}

Between 8 June and 2 July 2002, the Hayman Fire burned more than 55,000 ha within the South Platte River drainage on the Front Range of the Rocky Mountains between Denver and Colorado Springs, Colorado (Graham, 2003) (Fig. 1). The South Platte River flows from southwest to northeast through the burned area, with the Cheesman Reservoir (a municipal water source) at risk for contamination via runoff and erosion. The long-term average annual precipitation is $400 \mathrm{~mm}$ at the Cheesman weather station (elevation $2100 \mathrm{~m}$ ) (Colorado Climate Center, 2004). Elevations within the burned area extend to over $3000 \mathrm{~m}$ and precipitation at higher elevations is likely to be greater than that measured at the weather station. The region is semi-arid, with a late summer monsoon season characterized by short-duration, high-intensity storms. The region is underlain by the granitic Pikes Peak batholith, with frequent rock outcrops (Cipra et al., 2003). The main soil types are Sphinx and Legault series, which are coarse-textured sandy loams, gravelly sandy loams and clay loams (Cipra et al., 2003; Robichaud et al., 2003). The dominant tree species are ponderosa pine (Pinus ponderosa) and Douglasfir (Pseudotsuga menziesii) (Romme et al., 2003).

An initial burn severity map of the Hayman Fire was created from a 16 June 2002 SPOT image (Annette Parsons, pers. comm., 2005 ) because Landsat data were not immediately available. This burn severity map was used by rapid response postfire assessment teams to guide postfire stabilization and rehabilitation planning, but within the scope of this project, the map was used only to select ground plot locations (Fig. 1). Landsat data were used at a later date to calculate initial and 1-year postfire (extended) dNBR 


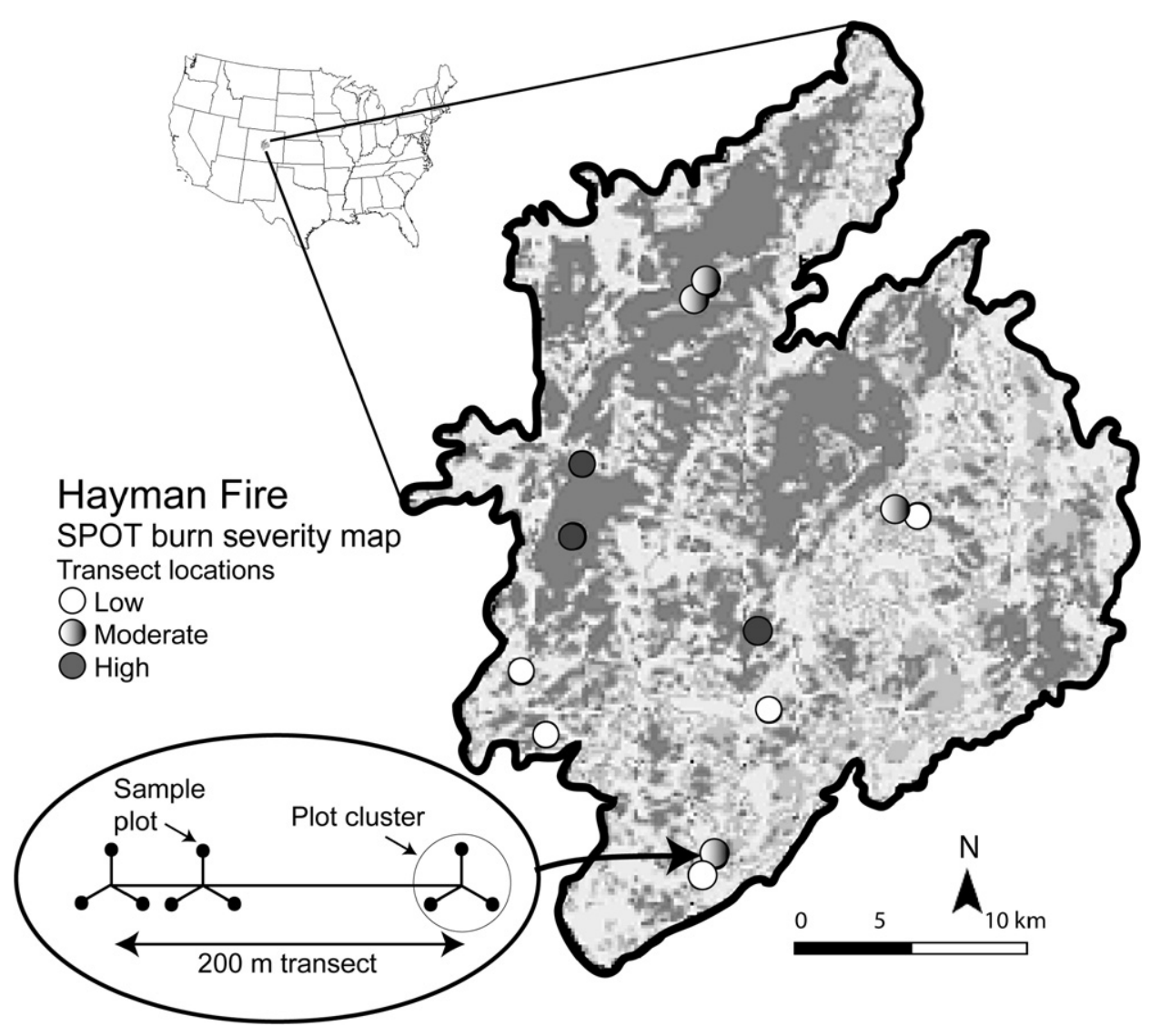

Fig. 1. Burn severity map of the Hayman Fire. Transect locations and an example transect layout is shown.

values. The initial dNBR values were classified to create a Burned Area Reflectance Classification (BARC) map. The available cloud-free dates of the Landsat pre-fire, immediate postfire, and 1year postfire images were 12 May 2001, 2 July 2002, and 11 June 2003, respectively. In this study, we compare the BARC map and dNBR values to the ground data and hyperspectral data.

\section{Data acquisition}

\subsection{Ground measurements}

Ground reference validation data were collected between 17 July and 2 August 2002. Approximately 60 sample plots were selected in each of the three burn severity classes as delineated by the BAER burn severity map. East-west transects were established in visually homogenous burn sites at least $20 \mathrm{~m}$ from roads. The transects were intended to be $200 \mathrm{~m}$ in length (Fig. 1), with central reference plots at $0 \mathrm{~m}$ (west endpoint), $50 \mathrm{~m}$, and $200 \mathrm{~m}$ (east endpoint). The locations of the central reference plots were located with a GPS unit. At each reference point three $20 \mathrm{~m}$ radials were established at 0,120 and $240^{\circ}$, respectively, with a tape and a compass. The sample plots were $4 \mathrm{~m}$ in diameter at the end of each of these radials. These groups of three plots are referred to as plot clusters.

The actual transect lengths were between 50 and $400 \mathrm{~m}$, depending on topography and the uniformity of burn severity. The shorter transects only had reference points at each end, while the longer transects had reference points at the endpoints as well as at $50 \mathrm{~m}$ from the west endpoint, and in the case of the $400 \mathrm{~m}$ transect, at $250 \mathrm{~m}$ from the west endpoint. In the low burn severity class there were three $50 \mathrm{~m}$ transects with six plots each and five $200 \mathrm{~m}$ transects with nine plots each, for a total of 63 plots along eight transects. In the moderate burn severity class there were six $200 \mathrm{~m}$ transects and one $50 \mathrm{~m}$ transect for a total of 60 sample plots along seven transects. In the high burn severity class, there were five $200 \mathrm{~m}$ transects and one $400 \mathrm{~m}$ transect for a total of 60 sample plots along six transects. The spatial and directional layout of the transects and sample plots was designed to encompass the spatial variability of the field measurements by sampling at short and long distances between sample plots (35 to $435 \mathrm{~m}$ apart) as well as sampling in different directions so that variation from slope position would be captured. Measurements from the 3 plots were averaged to the plot cluster scale, to minimize spatial variability at a finer scale than the geolocational certainty of the hyperspectral imagery.

Fractional cover of all present ground cover components was visually estimated within the 4-m circle at each plot. Minor ground cover fractions, which were often grasses, forbs, shrubs, woody debris, or stumps were estimated first. A value of 1\% was recorded if there was a trace of the material within the plot. The more abundant fractional ground cover components (exposed mineral soil and rock, ash, and litter) were then estimated in 5\% increments with the largest cover component estimated last. All cover fractions were required to sum to unity. Exposed mineral soil and rock were considered ground cover for the purpose of accounting for all physical space within a plot. New litter, mostly postfire needlecast 
from scorched trees, was estimated separately from scorched litter that was present at the time of the burn to best capture the ground conditions immediately after the fire. Thus, new litter was not included in the cover fractions that summed to unity. Percent green and percent char (scorch) of all ground cover ( $<1 \mathrm{~m}$ high) components were later calculated, and percent soil and rock were added together into an inorganic cover fraction, to better test correlations between the ground and hyperspectral image data. For clarity, the combination of soil and rock will be referred to as soil or soil cover.

The number of trees, their species, height, diameter, crown ratio, and percent green, brown and black crown were measured in the 7 $m$ circle. To estimate the percent of the plot that was occluded by overstory canopy vegetation, four densiometer measurements were taken, one in each of the four cardinal directions, at the edge of the 4-m circle plot. The mean percent canopy cover was calculated from these four measurements and was applied to the entire plot, with the remainder considered understory, or ground cover. The fractions of green and scorched canopy vegetation were calculated as a percent of the total canopy cover of the plot and added to the surface vegetation measurements. For clarity, 'ground' data from this point on refers to surface combined with canopy vegetation measurements at each plot.

\subsection{Field spectrometer data}

From 17-19 July 2002, bright-target ground-calibration field spectra were collected through cooperation with the US Geological Survey, using an ASD (Analytical Spectral Devices ${ }^{1}$, Boulder, Colorado, USA) Pro-FR field spectroradiometer. Spectra were collected with the bare tip foreoptic from a height of $\sim 1 \mathrm{~m}$ (FOV $22^{\circ}$ ), and were assumed to be reasonably homogenous at that resolution. The ASD Pro-FR reports reflectance for 2151 channels at $1-\mathrm{nm}$ spacing over the $350 \mathrm{~nm}$ to $2500 \mathrm{~nm}$ wavelength range, spanning nearly the same portion of the EM spectrum as the Probe I sensor used for airborne imaging. The field spectroradiometer was calibrated against a Spectralon (Labsphere ${ }^{1}$, North Sutton, New Hampshire, USA) 100\% reflective panel immediately before and at frequent intervals during field spectra collection. Spectralon is a bright calibration target with well-documented reflectance in the $400 \mathrm{~nm}$ to $2500 \mathrm{~nm}$ region of the EM spectrum, and is used to convert relative reflectance to absolute reflectance. An absorption feature at $2130 \mathrm{~nm}$ unique to Spectralon was corrected before the field spectra were related to the image spectra (Clark et al., 2002). The calibration field spectra were collected over spectrally homogenous granitic rocks on the north shore of the Cheesman Reservoir. All spectra were inspected for quality, and outliers were discarded. The mean spectrum of $\sim 200$ granitic rock spectra was convolved to the bandwidth wavelengths of the Probe I sensor.

\subsection{Airborne hyperspectral imagery}

Fourteen adjacent flight lines of airborne hyperspectral imagery were collected on 10 August 2002 over the Hayman

\footnotetext{
1 Trade names are included for the benefit of the reader and do not imply endorsement by the US Department of Agriculture.
}

Fire between 1630 and 1900 UTC (solar noon 1905 UTC). The Probe I whisk-broom sensor was flown at $2100 \mathrm{~m}$ AGL and collected data along a track $\sim 28 \mathrm{~km}$ long and $2.3 \mathrm{~km}$ widecorresponding to a 512 pixel-wide swath with each pixel $5 \mathrm{~m}$ by $5 \mathrm{~m}$ at nadir. Reflected EM energy from the surface was received in 128 contiguous spectral bands that spanned $432 \mathrm{~nm}$ to $2512 \mathrm{~nm}$, with a spectral bandwidth of $11 \mathrm{~nm}$ to $19 \mathrm{~nm}$. An on-board GPS and inertial measurement unit (IMU) acquired geolocation data that were matched with the spectral data collection. The geolocation data, together with 30-m digital elevation models, were used to generate Input Geometry (IGM) files, which were later used to georeference the results.

Ideally, the hyperspectral imagery would have been acquired simultaneously with the field spectra and ground data, but smoke, weather, and logistical issues made a time delay unavoidable. The most likely differences in the ground conditions between the times that the ground data and airborne imagery were collected are ash removal and char redistribution due to wind and rain, increased needlecast on the ground, and green revegetation, particularly near water sources. We were not able to measure the percent change of any of these differences at the plots; however, casual field observations during this time period and at the time of image acquisition suggested that changes in these conditions were minor and that the image captured the approximate ground conditions at the time of ground data collection.

\subsection{Atmospheric correction of hyperspectral data}

The airborne hyperspectral data were converted to reflectance using ACORN software (Atmospheric CORrection Now,

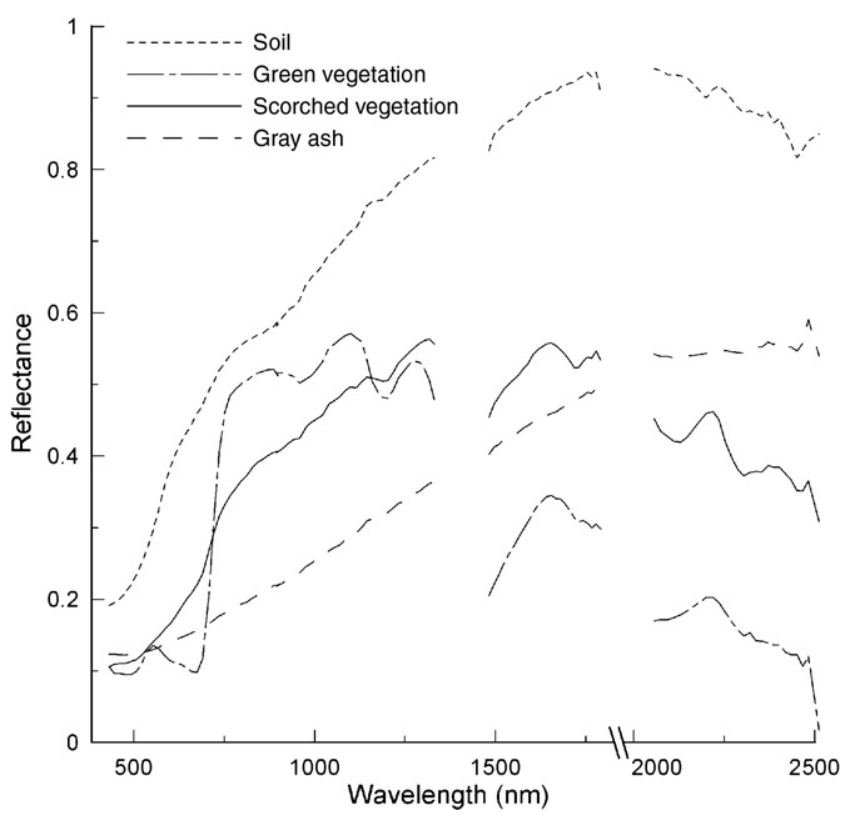

Fig. 2. Spectral reflectance of the image-derived endmembers that were used in the MTMF unmixing process. The soil spectrum is a bright, high albedo spectrum that is abundant in the Hayman Fire area. Gray ash is a mixture of white ash and black char. Scorched vegetation is charred and nonphotosynthetic, while green vegetation is still alive one month after the fire. 


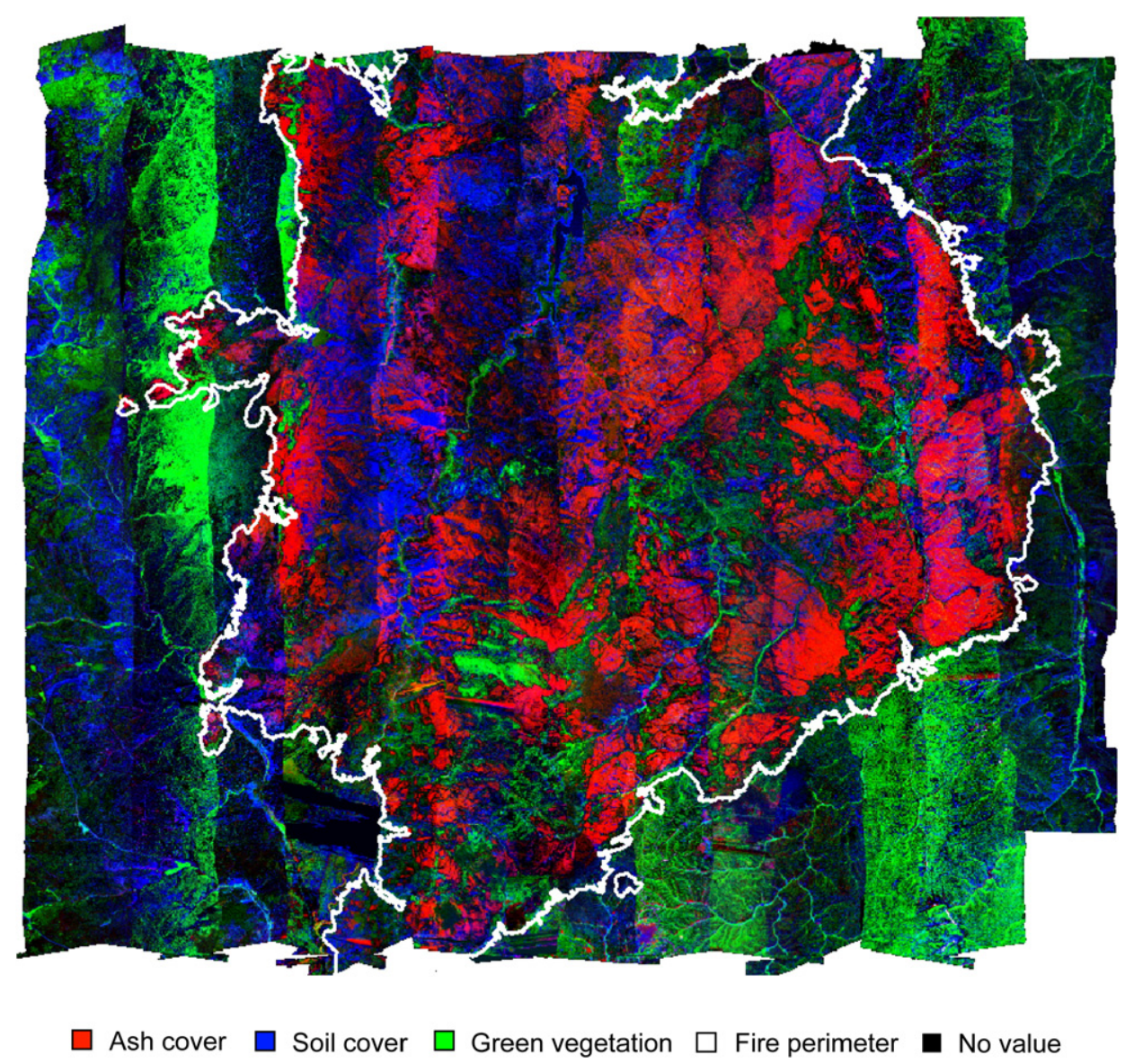

Fig. 3. Red, green, blue (RGB) color composite of the unmixed image; the white line is the approximate fire perimeter for reference. Red pixels represent ash, green pixels represent green vegetation, blue pixels represent soil, and black pixels represent background material.

Analytical Imaging and Geophysics LLC, Boulder, CO) without any additional artifact suppression (Analytical Imaging \& Geophysics, 2002). ACORN uses a radiative transfer model to calculate atmospheric gas absorptions and scattering; these characteristics are then used to convert sensor radiance to

Table 1

Number of plots with target material present or detected $(n)$, means, medians, ranges and standard deviations (std.) of the measured ground cover and spectral values (MTMF scores) of each endmember classified by soil burn severity

\begin{tabular}{|c|c|c|c|c|c|c|c|c|c|}
\hline \multirow{2}{*}{$\begin{array}{l}\text { Ground } \\
\text { cover }\end{array}$} & \multirow{2}{*}{$\begin{array}{l}\text { Burn } \\
\text { severity }\end{array}$} & \multicolumn{4}{|c|}{ Ground cover (\%) } & \multicolumn{4}{|c|}{ MTMF scores } \\
\hline & & $n$ & Mean & Range & Std. & $n$ & Mean & Range & Std \\
\hline \multirow[t]{3}{*}{ Ash } & Low & 20 & 15 & $0-36$ & 10 & 13 & 7 & $0-31$ & 10 \\
\hline & Moderate & 20 & 12 & $4-30$ & 7 & 16 & 8 & $0-25$ & 7 \\
\hline & High & 20 & 25 & $5-68$ & 17 & 18 & 26 & $0-89$ & 30 \\
\hline \multirow[t]{3}{*}{ Soil } & Low & 21 & 26 & $2-70$ & 18 & 18 & 2 & $0-22$ & 5 \\
\hline & Moderate & 20 & 46 & $5-81$ & 20 & 15 & 3 & $0-10$ & 3 \\
\hline & High & 20 & 56 & $22-85$ & 20 & 18 & 6 & $0-18$ & 6 \\
\hline \multirow{3}{*}{$\begin{array}{l}\text { Scorched } \\
\text { vegetation }\end{array}$} & Low & 21 & 55 & $2-89$ & 22 & 19 & 13 & $0-79$ & 19 \\
\hline & Moderate & 20 & 48 & $20-87$ & 19 & 17 & 23 & $0-59$ & 18 \\
\hline & High & 20 & 29 & $13-49$ & 9 & 19 & 4 & $0-21$ & 6 \\
\hline \multirow{3}{*}{$\begin{array}{l}\text { Green } \\
\text { vegetation }\end{array}$} & Low & 21 & 18 & $2-31$ & 9 & 19 & 11 & $0-43$ & 11 \\
\hline & Moderate & 20 & 6 & $0-23$ & 7 & 14 & 2 & $0-17$ & 4 \\
\hline & High & 12 & 1 & $0-5$ & 1 & 7 & 1 & $0-3$ & 1 \\
\hline
\end{tabular}

The total $N$ in each class is the number of plot clusters: low burn severity (21); moderate (20); high (20). apparent surface reflectance. The non-smoothed reflectance data were further refined with a radiative transfer groundcontrolled (RTGC) calibration (Clark et al., 2002). This process involved calculating a multiplier from the differences between the mean image-reflectance spectrum over the area where bright-target calibration field spectra were collected and the corresponding average field-reflectance spectrum. The multiplier was then applied to each flight line of ACORN corrected image-reflectance data separately (Laes et al., 2004). Due to the geographic extent of the data and the changes in atmospheric conditions in the time required to acquire all 14 flight lines, residual atmospheric effects were still apparent in the corrected data. Thus, each flight line was processed and analyzed separately to avoid exacerbation of these residual differences.

\section{Data analysis}

\subsection{Image analysis}

Eleven water vapor bands near $1400 \mathrm{~nm}$ and $1900 \mathrm{~nm}$ and two other noisy bands ( $895 \mathrm{~nm}$ and $2512 \mathrm{~nm}$ ) were excluded from image analysis. The remaining 115 bands of RTGCcorrected image-reflectance data were reduced further with the Minimum Noise Fraction (MNF) transformation to $20 \mathrm{MNF}$ 
a)

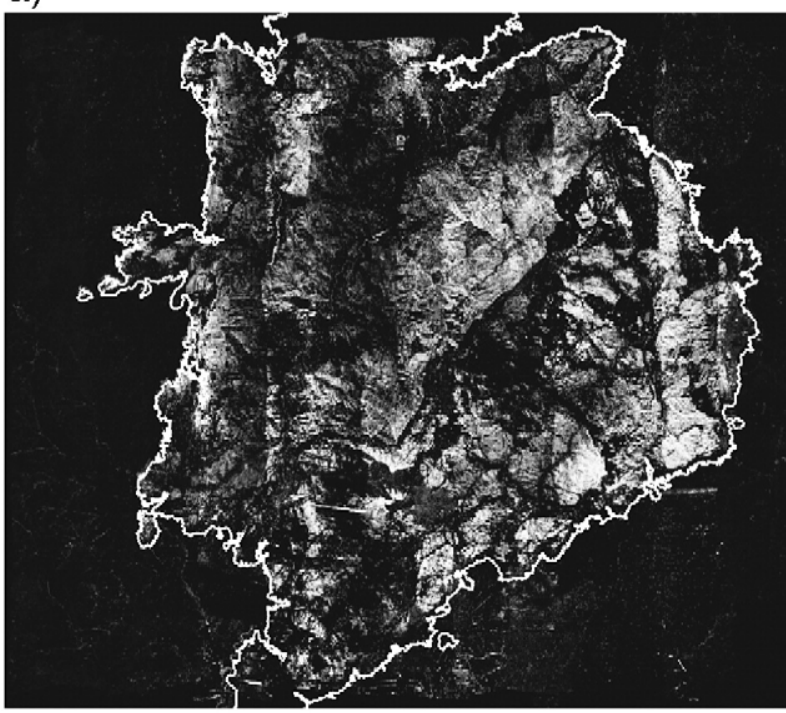

c)

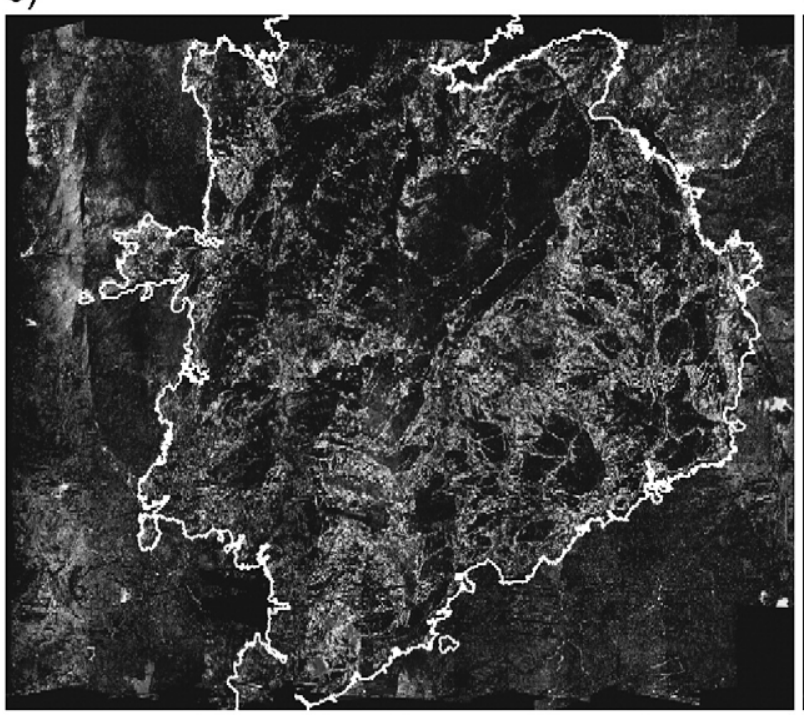

b)

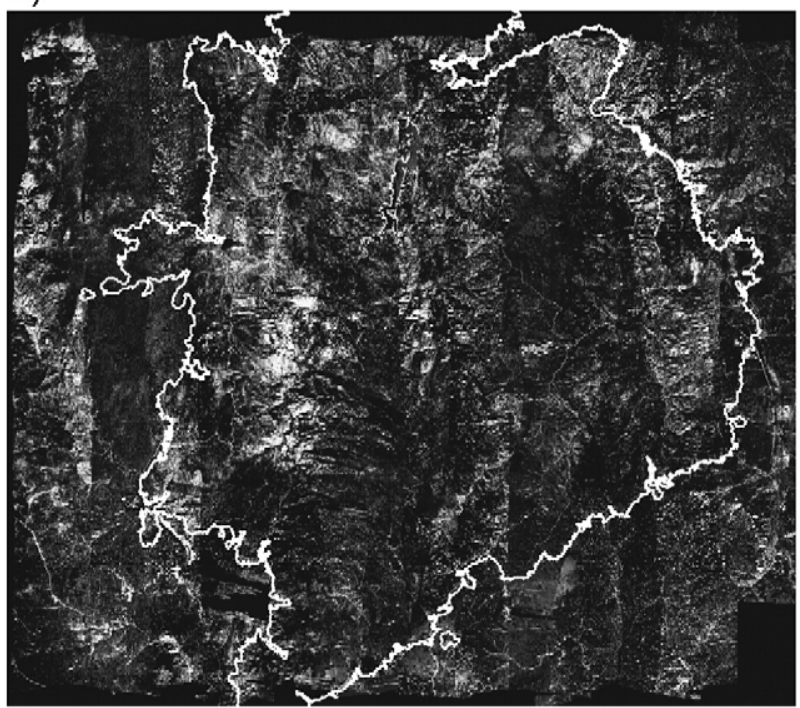

d)

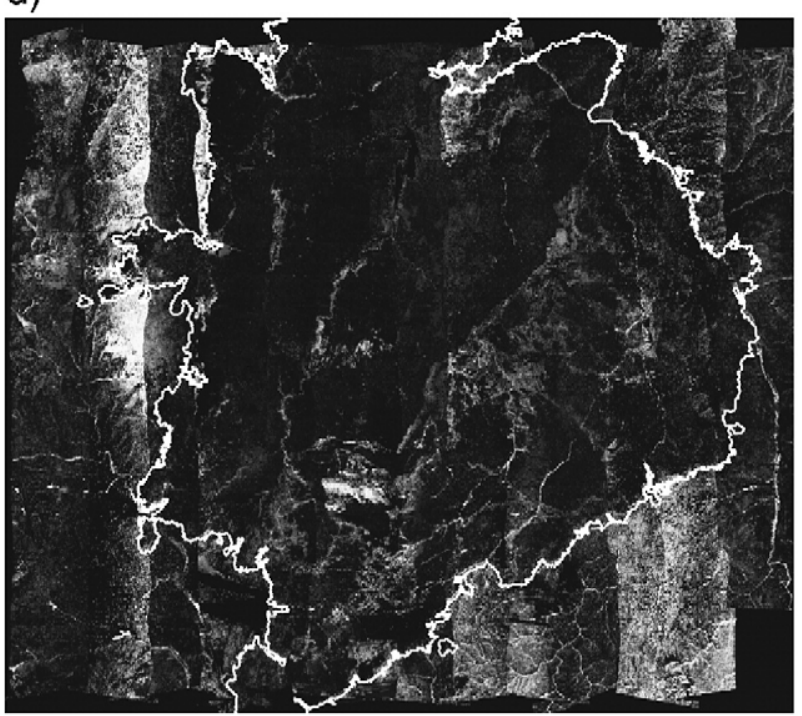

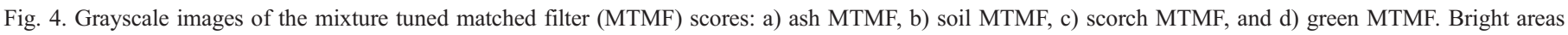
represent higher fractional cover; scale is $0-1$. An approximate fire perimeter (white line) is shown for reference.

bands. The MNF transformation is essentially a two-phase principal component analysis that segregates the noise from the data resulting in a reduced number of bands containing the most meaningful information (Green et al., 1988). The first $20 \mathrm{MNF}$ bands were evaluated based on the associated eigenvalues and determined to have the most spectral information and the least amount of noise. The MTMF partial-unmixing algorithm (Boardman, 1998) was applied to the 20 MNF-transformed bands on all 14 flight lines separately.

A library of image-derived endmembers representing gray ash (a mixture of white ash and black char), soil, and scorched and green vegetation was created for each flight line for use in the unmixing process. The endmembers were identified using the Pixel Purity Index (PPI) routine (Boardman et al., 1995) in ENVI (Environment for Visualizing Images) software (Research Systems Inc., Boulder, CO). The purest pixels, containing one homogenous cover type, in each flight line were identified with the PPI. By examining the spectral signature of each pixel and our a priori knowledge of most of the fire area we were able to select pixels in each flight line that represented ash, soil, scorched and green vegetation. The mean spectral signature of the pure pixels in each class was calculated for use in the spectral unmixing. These endmembers from flight line 7 are shown in Fig. 2. All the libraries were transformed to MNF space using the same statistics file as derived from the MNF transformation of the corresponding flight line. By creating a different library for each flight line, any residual atmospheric effects (after the RTGC calibration) were present in both the library and the corresponding flight line, thus minimizing their effect on the unmixing process. A disadvantage of this method is that a slightly different library was used for each flight line, somewhat reducing the consistency from one flight line to the next, which is apparent in the mosaicked image (Fig. 3).

Two gray-scale output images were produced for each input spectrum on each flight line: a matched filter score and an 
Table 2

Pearson correlation coefficients $(r)$ between ground and image data ( $n=61$ plot clusters)

\begin{tabular}{|c|c|c|c|c|c|c|c|}
\hline \multirow[t]{2}{*}{ Ground cover } & \multicolumn{5}{|c|}{ Hyperspectral imagery } & \multicolumn{2}{|l|}{ Landsat imagery } \\
\hline & Green MTMF & Scorch MTMF & Ash MTMF & Soil MTMF & NBR & Immediate dNBR & Extended dNBR \\
\hline Green vegetation (\%) & 0.70 & - & -0.29 & -0.35 & 0.76 & -0.76 & -0.68 \\
\hline Litter $(\%)$ & 0.53 & 0.27 & - & -0.49 & 0.76 & -0.71 & -0.48 \\
\hline New litter $(\%)$ & - & 0.69 & -0.29 & - & 0.29 & -0.24 & -0.19 \\
\hline Scorched vegetation (\%) & 0.29 & 0.46 & - & -0.32 & 0.53 & -0.49 & -0.25 \\
\hline Ash $(\%)$ & - & - & 0.65 & - & -0.36 & 0.44 & 0.50 \\
\hline Soil (\%) & -0.53 & -0.25 & - & 0.47 & -0.62 & 0.50 & 0.24 \\
\hline
\end{tabular}

Non-significant correlations are denoted by $(-)$, other correlations are significant at $p$-value $<0.05$.

infeasibility value (Boardman, 1998). The MTMF score indicates how well the image pixel compares to the library reference spectrum and measures how spectrally abundant that material is in the image pixel. Spectral abundance in an image pixel corresponds to physical abundance in the same location on the ground. A score of zero means no match to the input endmember and no presence of the material in a pixel, while a score closer to one indicates a better match to the input endmember and greater abundance of the material in the pixel. The infeasibility (IF) value shows how likely or unlikely the match is. In general, pixels that combine higher MTMF scores with low IF values are a better match to the endmember spectrum. A scatterplot of MTMF score versus infeasibility is used for the selection of pixels that best match the library reference spectrum and to eliminate pixels where high IF values occurred with positive MTMF scores (i.e., false positives) (Laes et al., 2004).

As the MTMF routine is a partial-unmixing process, the sum of the MTMF scores at each pixel was almost always less than unity because unidentified background material existed in nearly every pixel. The MTMF routine projects the mean of the background data to zero (i.e., half of the background will have negative values). Negative MTMF scores or MTMF scores greater than 1 (for at least one of the four endmembers) were present on $\sim 90 \%$ of pixels, both of which are physically meaningless. These values were re-scored as 0 or 1 to indicate no match or a perfect match, respectively, to the input endmember. Finally, all MTMF scores were multiplied by 100 to assess the 1:1 correlations with the ground data.

Once each flight line was unmixed, the resulting score and infeasibility images were georeferenced, and all the flight lines were combined into a single image mosaic. This image contained eight continuous gray-scale bands: IF and score images for each of the component spectra of ash (ash score), scorched vegetation (scorch score), green vegetation (green score), and soil (soil score). The mosaicked image revealed location discrepancies between features on adjacent flight lines. Where the flight lines overlap, up to 30-m (6-pixel) differences were visible. Fortunately, most of the ground plots did not fall in these overlap regions between flight lines. To evaluate the accuracy of the georeferenced image, distances and directions to road intersections were measured for about half of the transects, and errors of $5 \mathrm{~m}$ to $10 \mathrm{~m}$ (1-2 pixels) were found to be common. To compensate for some of the geolocational uncertainty and the effects of surrounding pixel radiance, pixel values within a 5-m radius footprint around each plot location were averaged. Similarly, the means of 3 MTMF scores and $3 \mathrm{dNBR}$ values (extracted from the BARC map) were calculated for each 3 plot cluster in the same manner as was done for the ground data so that all data were being compared at the same spatial scale.

NBR values were calculated from the hyperspectral imagery using approximately the same wavelengths that van Wagtendonk et al. (2004) used to calculate dNBR with AVIRIS data. These wavebands, at $780 \mathrm{~nm}$ and $2371 \mathrm{~nm}$, correspond to Landsat bands 4 and 7, respectively (see Eq. (1)). As only postfire hyperspectral data were available, the differenced NBR (dNBR) values were not calculated. The hyperspectral NBR values were extracted at the plot locations and averaged for each plot cluster.

\subsection{Statistical analysis of unmixing results relative to ground measurements}

Detailed ground observations from the 61 plot clusters were used to evaluate the image unmixing results. Correlations between the 61 ground data values and the spectral abundance from the unmixing results (MTMF scores) were assessed for each endmember using the Pearson correlation statistic (SAS Institute Inc., 1999). Correlations between ground data and the hyperspectral NBR values, and the Landsat-derived dNBR (immediate and extended) values were also calculated, and all correlations were regarded as significant when $p$-value $<0.05$. Linear regressions (SAS proc REG) with ground data as the independent variables and spectral data as the dependent variables were used to further examine the relationship between the ground and spectral data.

\section{Results}

\subsection{Comparison of unmixing results with ground measurements}

The presence of ash was spectrally detected in 47 of the 60 plot clusters that had ash present. Green and scorched vegetation were accurately detected in 40/53 and 55/61 of the plots, respectively, and at least a trace of soil was spectrally detected in 51/61 plots with soil or rock present (Table 1). MTMF scores of the selected endmembers were abundant across the entire image, especially within the fire perimeter (Fig. 4). The means and medians of the measured ground values were generally higher than the corresponding MTMF scores (Table 1 and Fig. 5), yet the positive 
a)

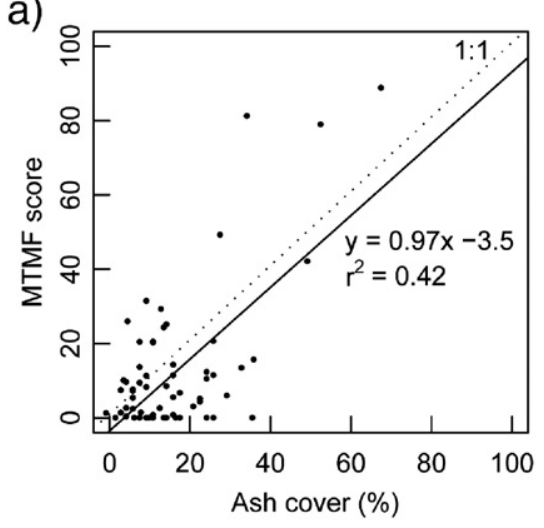

c)

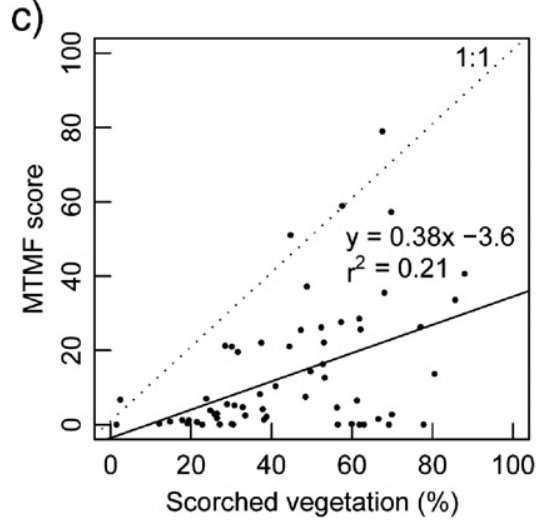

b)

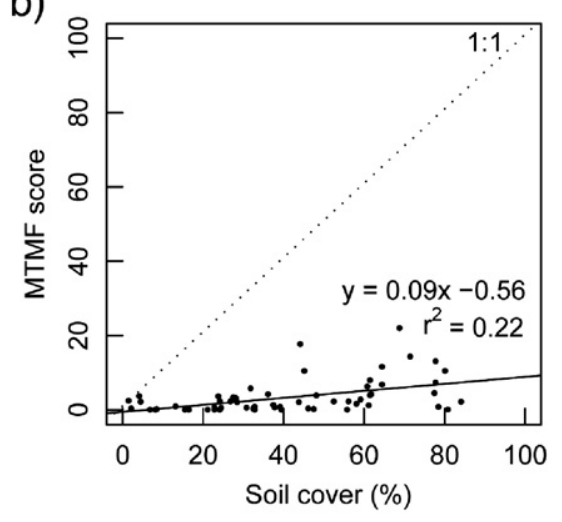

d)

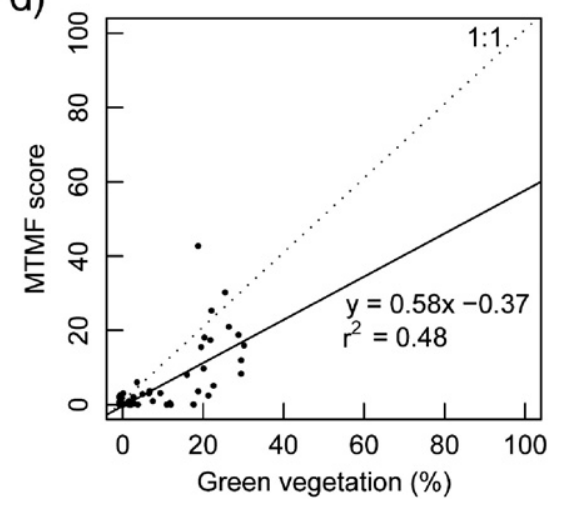

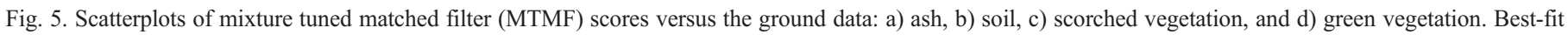
linear regression lines are shown as solid lines while a 1:1 line is shown as a dotted line.

correlations between the ground measurements and the MTMF scores indicated that as more of a material was measured on the ground, the MTMF scores increased as well (Table 2).

The strongest correlation between a ground measurement and MTMF score was green vegetation $(r=0.70)$, which can be attributed to the relative ease of detecting the canopy vegetation with an airborne sensor (Table 2). Green MTMF scores were also significantly correlated with litter $(r=0.53)$, which may reveal a certain amount of moisture or greenness left in some of the litter on the ground, most likely in the areas burned at low severity. Litter $(r=0.27)$, new litter $(r=0.69)$, and scorched vegetation $(r=0.46)$ had the strongest correlations with the scorch MTMF score; these were the driest and partially charred vegetation components. Percent soil and rock had a significant correlation with the soil MTMF score $(r=0.47)$. Ash was the only variable positively correlated with the ash MTMF score $(r=0.65)$. In the areas with more prevalent ash cover, MTMF was an even better predictor. When ash cover exceeded $25 \%$, the correlation with MTMF was 0.74 while the correlation with dNBR was 0.48 . When ash cover was less than $10 \%$, the correlation with MTMF was 0.10 while the correlation with $\mathrm{dNBR}$ was only 0.02 (although neither correlation is statistically significant at $p<0.05)$.

The NBR values from the hyperspectral imagery were significantly correlated to all of the major ground cover classes (Table 2). The strongest correlations were with green vegetation and litter $(r=0.76)$. The weakest correlations were with new litter $(r=0.29)$ and scorched vegetation $(r=0.53)$. NBR values were negatively correlated with ash $(r=-0.36)$ and soil $(r=-0.62)$.

When NBR values are differenced (dNBR), low values are classified as low burn severity and values increase as the severity of the burn, or the magnitude of change from pre-fire conditions, increases. The strongest negative correlations between immediate dNBR values and the ground data were with green vegetation $(r=$ $-0.76)$ and litter $(r=-0.71)$ (Table 2$)$. As burn severity increased, the correlations between dNBR values and ash $(r=0.44)$ and soil $(r=0.50)$ became positive. The correlations between the extended dNBR values (1-year postfire) were similar to the immediate dNBR values, just slightly weaker (Table 2 ). The only correlation that was stronger was between the extended dNBR and ash $(r=0.50)$.

The results from the linear regressions show that the ground cover and MTMF scores for all four endmembers were statistically related and that MTMF scores may be used to quantitatively predict ground cover components (Fig. 5). Ash and green vegetation had the strongest relationships and the closest 1:1 fit with the MTMF scores (Fig. 5a, d). For comparison, the results of the linear regressions between the ground data and the dNBR values showed that as ash $\left(r^{2}=0.20\right)$ and soil $\left(r^{2}=0.25\right)$ increased, so did the dNBR values and the overall burn severity (Fig. 6a and b). As scorched $\left(r^{2}=0.23\right)$ and green vegetation $\left(r^{2}=0.58\right)$ increased, dNBR values decreased along with burn severity (Fig. $6 \mathrm{c}$ and d). The $r^{2}$ coefficients were similar to those for the regressions with MTMF scores for soil $\left(r^{2}=0.22\right)$ and scorched vegetation $\left(r^{2}=0.21\right)$ (Fig. $\left.5 b, c\right)$. MTMF scores are a 
a)

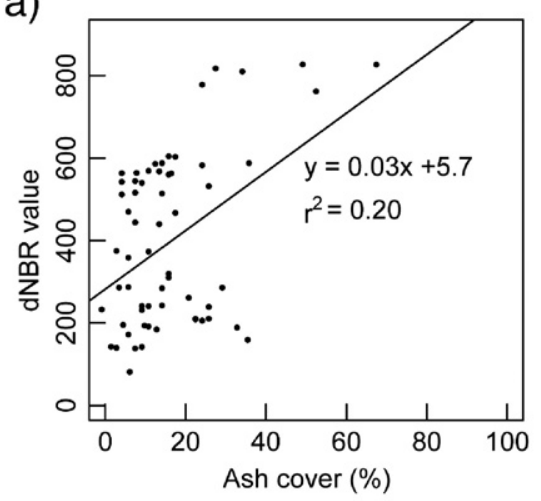

c)

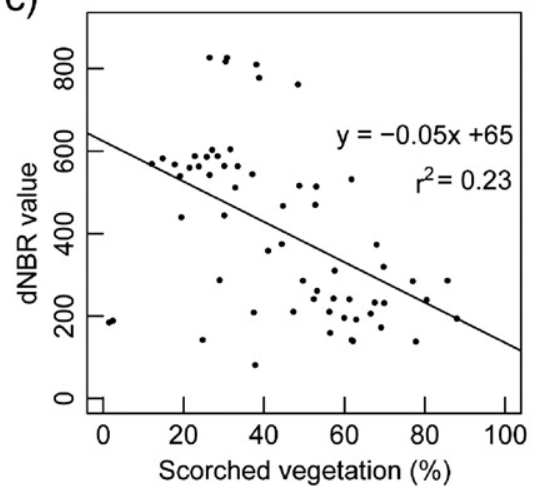

b)

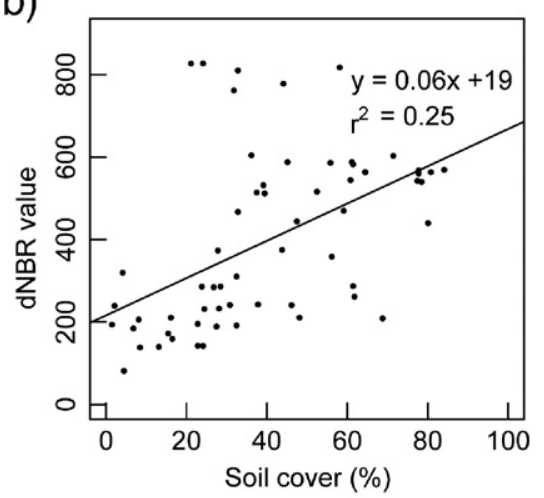

d)

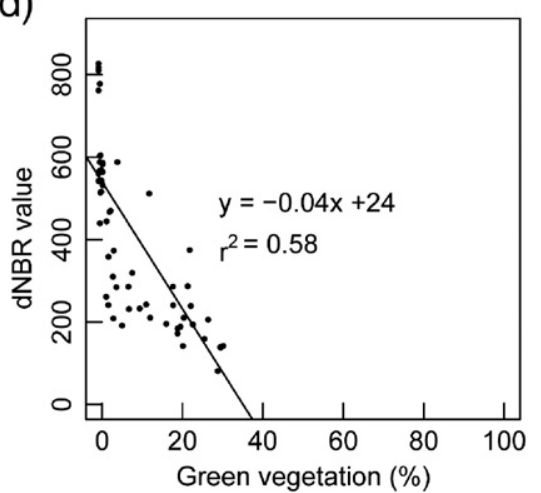

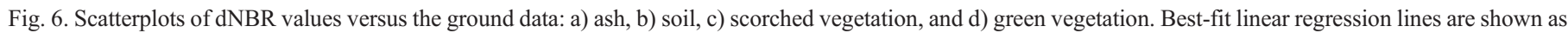
solid lines.

better predictor of ash $\left(r^{2}=0.42\right)$, while dNBR values are better predictors of green vegetation.

\subsection{Postfire maps and spatial distribution of ground cover components}

The individual gray-scale fraction maps (Fig. 4) for each input endmember may be viewed individually or in any combination in a red-green-blue (RGB) color composite image for simultaneous cover type detection (Fig. 3). The grayscale represents the MTMF scores: black areas have zero value, or no match to the input endmember, while the bright white areas have MTMF scores greater than 0.3 (or $\sim 30 \%$ cover in that pixel). Ash MTMF scores gave the best indication of the actual fire perimeter (Fig. 4a). There were few light pixels outside of the main fire area, and those that were outside were more of a gray color indicating a lower MTMF score and a poor match to the ash endmember. Fig. 4b represented soil abundance, both of which were widespread throughout the entire image, not just within the fire perimeter. The scorch MTMF score image (Fig. 4c) was similar to the ash MTMF score image (Fig. 4a) in that the fire perimeter is discernible, yet there are positive scorch MTMF scores outside the main fire region. Scorch MTMF scores were positively correlated with litter and new litter, both of which were present outside of the fire perimeter. Green vegetation abundance was clearly more prevalent outside of the fire area (Fig. 4d). Green vegetation occurred within the fire perimeter mostly along stream networks in valley bottoms. The outlines of some of the patches of ash visible in Fig. 4a can be seen both in Fig. 4c and d, which are remaining scorched and green vegetation in the transition areas between burned patches. The combination of individual components provided a better representation of the effects of the fire, as each of the individual components (except for ash) were found abundantly outside the main burned area.

The RGB (red, green, blue) color composite (Fig. 3) created from layering individual unmixing results identified and quantified relative ash, green vegetation, and soil. Ash was indicated by red while exposed soil was a blue color, mixing the two resulted in a purple or magenta color (Fig. 3). Green vegetation was shown by the brightest green color and was typically mixed with scorched vegetation, shown by a much darker green color (Fig. 3). The fire perimeter was highlighted on the northwest and southeast sides by extreme transitions from ash to green vegetation. Low and moderate severity areas were characterized by remaining green and scorched vegetation; these areas were typically heterogeneous and had mixed patches of both ash and soil (Fig. 3).

\section{Discussion}

\subsection{Comparison of unmixing results with ground measurements}

The identification and quantification of postfire ground cover characteristics can be used to estimate immediate postfire 
effects and potential watershed response. Remotely sensed data can provide this information with varying degrees of accuracy. Although the correlations between the ground data and the MTMF scores were comparable to the correlations between the ground data and the NBR and dNBR values (Table 2), an MTMF score provided quantitative and more physically meaningful information than a dNBR value. The positive correlations between the ground data and the MTMF scores suggested that MTMF scores can detect vegetation, ash, and soil components on the ground with a modest degree of certainty ( $r=0.5$ to 0.7$)$. The ability to identify postfire ash is perhaps the most significant improvement over previous mapping methods. White ash is indicative of complete surface vegetation combustion, and is most prevalent in the severely burned areas of a fire (Landmann, 2003; Smith et al., 2005). While there were significant correlations between the NBR and dNBR values with ash, these generally indicated that ash occurred in areas where the canopy vegetation had burned at high severity. The ability to map ash and char, or a mix of the two (gray ash), on the ground is an improvement over previous methods. Burned areas with little or no remaining vegetative cover may be targeted for postfire stabilization and rehabilitation, while areas with remaining ground cover (litter, new litter, or green vegetation) may recover naturally and more quickly and have little need for postfire treatments.

Ideally, an MTMF score represents a physical percentage of a material on the ground-surface, and a best-fit line of MTMF scores versus the ground data would have a slope close to 1.0. In this study, the MTMF scores were mostly lower than the values measured on the ground, which was mainly due to the partialunmixing algorithm; scores were not constrained to sum to unity. By the nature of the sampling design, the ground cover data did sum to unity. If the target material (endmember) was not found in the pixel, the pixel was classified as background material (Boardman et al., 1995). The 183 ground plots were aggregated to 61 plot clusters that spanned the range of burn severities found within the burned area. Thus, every endmember was not found in every pixel, which resulted in many zeros on the endmember scatter plots (Figs. 5 and 6). The soil MTMF scores were particularly low, which may be attributed to vegetation (both canopy and understory) occlusion of the soil surface (Fig. 5b). When ground data were collected, at least $10 \%$ new litter covered the soil surface on $40 \%$ of the plot clusters, but the percent soil exposed was estimated beneath the new litter cover. By the time the image was acquired, $\sim 2$ weeks after the end of field data collection, there was likely additional needlecast, further obstructing the soil surface imaging capabilities.

Overall, the MTMF scores of each of the endmembers, ash, soil, scorched and green vegetation, were significantly related to and representative of the measured ground data. The hyperspectral data were acquired more than 1 month after the fire and during that time a few storms caused some runoff and erosion, which changed surface conditions by redistributing ash and litter. Stronger correlations may have been found if the ground data and image data were collected concurrently. In addition, the inability to precisely georegister the image made it necessary to compare the MTMF scores to aggregated plot cluster areas rather than single pixel or plot locations.
Similar to the results in van Wagtendonk et al. (2004), the NBR values that were calculated using the hyperspectral data provided similar or slightly stronger correlations with the ground data than the dNBR values from Landsat data (Table 2). Hyperspectral NBR was significantly correlated to all of the major ground cover classes, each of which is indicative of the degree of burn severity. However, the difference between the Landsat-derived dNBR values and the hyperspectral NBR values was minimal, and would not justify the greater acquisition cost or processing time of hyperspectral data versus Landsat data. If only calculating NBR, the most significant benefit of hyperspectral data over Landsat data, would be the finer scale of the hyperspectral imagery. The hyperspectral NBR provides an estimate of burn severity at a $5 \mathrm{~m}$ scale rather than the $30 \mathrm{~m}$ scale available with Landsat imagery. This higher resolution would allow for more precise postfire stabilization and rehabilitation planning.

\subsection{Postfire maps and spatial distribution of ground cover components}

Burned areas with either dominant ash cover or mixed soil and ash would likely be classified as high soil burn severity. Dominant ash or soil cover indicates that little vegetation remains on the ground to protect the soil from wind or water, and as a consequence, the area has an increased potential for postfire runoff and erosion. In this study, ash was the endmember that best corresponded to the perimeter of the burned area and was the strongest indicator of high burn severity. Ash can vary in color from white to dark gray, depending on the combination of ash and char (Landmann, 2003). Fires of different combustion efficiencies produce combustion residues of variable reflectance, from dark colored char, indicating incomplete combustion, to brighter ash, for efficient combustion (Trigg \& Flasse, 2001). The ash endmember used in this analysis was a gray ash endmember. The ash signature was selected from patches of pure pixels that appeared light gray (when the image was displayed in true color) with no remaining vegetation in the area. There are few published spectra of mixed ash; Landmann (2003) published a range of ash spectra from $9 \%$ white ash (89\% black char) to $100 \%$ white ash. Smith et al. (2005) also published black and white ash spectra. When these spectra were compared to the ash endmember used in this analysis, we confirmed our endmember was a mixture of white ash and black char, however, it is difficult to determine an approximate ratio of the two.

The other typical indicator of high burn severity is newly exposed soil and rock. However, the Hayman Fire area is a dry, mixed ponderosa pine and Douglas-fir forest with sparse vegetation in many places as well as numerous rocky outcrops; thus, it is expected that soil and rock will be detected throughout the image regardless if the area burned. Therefore, ash was a better indicator of effects directly from the fire. Often, a combination of ash and soil can be used to evaluate the fireinduced physical changes of the ground-surface and derive an indication of the fire's effect on the soil. Kokaly et al. (2006) made similar correlations between mapped postfire ash and soil 
cover and the increased potential for runoff and erosion after the Cerro Grande Fire in New Mexico. Regions that are at the greatest risk of erosion are the areas where all vegetative ground cover has been removed by the fire, i.e., ash or soil.

These results suggest that the ability to map discrete physical ground cover characteristics (ash, soil, scorched and green vegetation) using hyperspectral imagery surpasses the capabilities of conventional multispectral burn severity mapping for identifying areas with and without remaining vegetation cover on the ground. Such a map would be useful in the time immediately following a fire to help evaluate and prescribe postfire erosion mitigation treatments.

\subsection{Hyperspectral data limitations}

Hyperspectral image data are useful to evaluate burned areas after wildfires. However, if this information is to be used to assist in postfire stabilization and rehabilitation decisions, then timely data acquisition and analysis are essential. Within this project, several operational issues became apparent: 1) because of logistical, weather, and safety concerns and the presence of smoke, image data are not easily acquired during or immediately after a fire; however, rapid image acquisition and data processing is essential if the image is to be used by postfire assessment teams (Orlemann et al., 2002). 2) In areas requiring large coverage, efforts must be made to maintain data quality and consistency between flight lines (Aspinall et al., 2002). 3) The large data files require that adequate personnel and computer time, data storage, and processing capabilities be available to produce a useful product. 4) And finally, the predictive power of any image-to-ground postfire assessment is limited ultimately by the presence of the overlying canopy. Ground-surface features are most clearly imaged when canopy cover is minimal, as the imaged vegetation fraction is proportional to the areal abundance of overstory canopy cover (Roberts et al., 1993).

All of these general limitations influenced this study. The analysis of the data required the generation of an individual reference library for each flight line. This cumbersome process resulted in a final mosaic that was not entirely "seamless." Therefore, it is likely that only a few of the endmember libraries may be useful on future fires in ponderosa pine and Douglas-fir forests on similar soils. Additional research is needed to develop an analytical procedure that can be used repetitively between flight lines and, ideally, between fires. However, the spectral endmembers types (ash, soil, scorched and green vegetation) that were used in the unmixing were representative of soil burn severity and were abundant on the ground plots within the image, and these same endmembers could be used to evaluate other burned areas.

\section{Conclusions}

The discrimination power of hyperspectral imagery allowed postfire materials to be characterized within a $5-\mathrm{m}$ pixel and their physical abundance quantified for a corresponding ground location. The hyperspectral unmixing results identified the relative abundance of ground components (ash, soil, scorched and green vegetation, litter and new litter) that were determined to be important for evaluating soil burn severity. The measured ground value of each component/endmember was significantly related to the corresponding spectral MTMF scores based on an assessment of 61 validation plots. Compared to Landsat data which is currently used for postfire assessment, the additional information provided by fine-scale hyperspectral imagery makes it possible to more accurately assess the effects of the fire on the soil surface. Quantifying ground cover characteristics, rather than classifying NBR values derived from satellite imagery, provided a better evaluation of the physical condition of the soil surface. These surface fire effects, especially soil and ash cover and the lack of any remaining vegetative cover, are indicative of potential watershed responses. However, because of logistical and safety concerns and the presence of smoke, field and image data are not easily acquired during or immediately after a fire. At the present time, using hyperspectral imagery to evaluate burned areas has great potential, but further research is needed to make these data products available for postfire rapid response assessments.

\section{Acknowledgements}

This research was supported by the US Department of Agriculture Forest Service Rocky Mountain Research Station and the US Department of Agriculture Forest Service and US Department of Interior Joint Fire Science Program (01C-2-1-02) as well as the National Science Foundation Integrative Graduate Education and Research Training grant (DGE-9972817) to the Center for Multiphase Environmental Research at Washington State University. We are grateful to Michael Parenti of M. Parenti \& Associates for his help in formulating the proposal; Annette Parsons with the US Department of Agriculture Forest Service Remote Sensing Applications Center and US Department of Interior Bureau of Land Management for her assistance with data collection and interpretative support; the US Department of Interior Geological Survey Spectroscopy Laboratory for the use of their spectroradiometer; the field crews who helped with data collection; and the internal and anonymous reviewer comments and suggestions.

\section{References}

Adams, J. B., Smith, M. O., \& Johnson, P. E. (1985). Spectral mixture modeling: A new analysis of rock and soil types at the Viking Lander 1 site. Journal of Geophysical Research, 91(B8), 8098-8112.

Adams, J. B., Sabol, D. E., Kapos, V., Filho, R. A., Roberts, D. A., Smith, M. O., et al. (1995). Classification of multispectral images based on fractions of endmembers: Application to land-cover change in the Brazilian Amazon. Remote Sensing of Environment, 52, 137-154.

Analytical Imaging, \& Geophysics LLC. (2002). ACORN 4.0 stand-alone version. Boulder, Colorado: Analytical Imaging and Geophysics LLC, 64 pp.

Aspinall, R. J., Marcus, W. A., \& Boardman, J. W. (2002). Considerations in collecting, processing, and analyzing high spatial resolution hyperspectral data for environmental investigations. Journal of Geographical Systems, 4, 15-29.

Boardman, J. W. (1998). Leveraging the high dimensionality of AVIRIS data for improved subpixel target unmixing and rejection of false positives: Mixture tuned matched filtering. In R. O. Green (Ed.), Summaries of the Seventh Annual JPL Airborne Earth Science Workshop, JPL Publication 97-1, 
12-16 January 1988, Pasadena, California (pp. 55-56). Pasadena: California Institute of Technology.

Boardman, J. W., Kruse, F. A., \& Green, R. O. (1995). Mapping target signatures via partial unmixing of AVIRIS data. In R. O. Green (Ed.), Summaries of the Fifth Annual JPL Airborne Earth Science Workshop, JPL Publication 95-1, 23-26 January 1995, Pasadena, California (pp. 23-26). Pasadena: California Institute of Technology.

Cipra, J. E., Kelly, E. F., MacDonald, L., \& Norman, J. (2003). Ecological effects of the Hayman Fire part 3: Soil properties, erosion and implications for rehabilitation and aquatic ecosystems. In R. T. Graham (Ed.), Hayman Fire case study analysis. Gen. Tech. Rep. RMRS-GTR-114 (pp. 204-219). Fort Collins, Colorado: US Department of Agriculture Forest Service, Rocky Mountain Research Station.

Clark, J., Parsons, A., Zajkowski, T., \& Lannom, K. (2003). Remote sensing imagery support for burned area emergency response teams on 2003 Southern California Wildfires. RSAC-2003-RPT1. Salt Lake City, Utah: US Department of Agriculture Forest Service, Remote Sensing Applications Center, 18 pp.

Clark, R. N., Swayze, G. A., Livo, K. E., Kokaly, R. F., King, T. V., Dalton, J. B., et al. (2002). Surface reflectance calibration of terrestrial imaging spectroscopy data: A tutorial using AVIRIS. In R. O. Green (Ed.), Proceedings of the 10th JPL Airborne Sciences Workshop, JPL Publication 02-1. Available online at http:// speclab.cr.usgs.gov/PAPERS.calibration.tutorial/

Cocke, A. E., Fule, P. Z., \& Crouse, J. E. (2005). Comparison of burn severity assessments using differenced normalized burn ratio and ground data. International Journal of Wildland Fire, 14, 189-198.

Colorado Climate Center. (2004). Colorado Climate Center data access. Fort Collins, Colorado: Colorado State University. Avaliable online at: http:// climate.atmos.colostate.edu/dataaccess.shtml

DeBano, L. F. (2000). The role of fire and soil heating on water repellency in wildland environments: A review. Journal of Hydrology, 231-232, 195-206.

DeBano, L. F., Neary, D. G., \& Ffolliott, P. F. (1998). Fire's effects on ecosystems. New York: John Wiley and Sons, $352 \mathrm{pp}$.

Epting, J., Verbyla, D., \& Sorbel, B. (2005). Evaluation of remotely sensed indices for assessing burn severity in interior Alaska using Landsat TM and ETM+. Remote Sensing of Environment, 96, 328-339.

Glenn, N. F., Mundt, J. T., Weber, K. T., Prather, T. S., Lass, L. W., \& Pettingill, J. (2005). Hyperspectral data processing for repeat detection of small infestations of leafy spurge. Remote Sensing of Environment, 95, 399-412.

Graham, R. T., technical editor (2003). Hayman Fire Case Study. Gen. Tech. Rep. RMRS-GTR-114 Fort Collins, Colorado: US Department of Agriculture Forest Service, Rocky Mountain Research Station, 404 pp.

Green, A. A., Berman, M., Switzer, P., \& Craig, M. D. (1988). A transformation for ordering multispectral data in terms of image quality with implications for noise removal. IEEE Transactions on Geoscience and Remote Sensing, 26(1), 65-74.

Hardwick, P., Lachowski, H., Maus, P., Griffith, R., Parsons, A., \& Warbington, R. (1997). Burned Area Emergency Rehabilitation (BAER) Use of Remote Sensing. RSAC-0001-TIP1. Salt Lake City, Utah: US Department of Agriculture Forest Service, Remote Sensing Applications Center.

Harris, A., Bryant, R. G., \& Baird, A. J. (2006). Mapping the effects of water stress on Sphagnum: Preliminary observations using airborne remote sensing. Remote Sensing of Environment, 100, 363-378.

Harsanyi, J. C., \& Chang, C. I. (1994). Hyperspectral image classification and dimensionality reduction: An orthogonal subspace projection approach. IEEE Transactions on Geoscience and Remote Sensing, 32, 779-785.

Hudak, A. T., Robichaud, P. R., Evans, J. B., Clark, J., Lannom, K., Morgan, P., et al. (2004). Field validation of Burned Area Reflectance Classification (BARC) products for post fire assessment. Remote Sensing for Field Users, Proceedings of the Tenth Forest Service Remote Sensing Applications Conference, Salt Lake City, Utah, 5-9 April 2004, unpaginated CD-ROM.

Ice, G. G., Neary, D. G., \& Adams, P. W. (2004). Effects of wildfire on soils and watershed processes. Journal of Forestry, 102(6), 16-20.

Jain, T. B., Pilliod, D. S., \& Graham, R. T. (2004, July-August). Tongue-tied. Wildfire, 22-26.

Jia, G. J., Burke, I. C., Goetz, A. F. H, Kaufmann, M. R., \& Kindel, B. C. (2006). Assessing spatial patterns of forest fuel using AVIRIS data. Remote Sensing of Environment, 102, 318-327.

Kokaly, R. F., Rockwell, B. W., Haire, S. L, \& King, T. V. V. (2006). Characterization of post-fire surface cover, soils, and burn severity at the
Cerro Grande Fire, New Mexico, using hyperspectral and multispectral remote sensing. Remote Sensing of Environment. doi:10.1016/j. rse.2006.08.006.

Laes, D., Maus, P., Lewis, S., Robichaud, P., \& Kokaly, R. (2004). Postfire burn-severity classification of the Hayman Fire CO: based on hyperspectral data. RSAC-0068-RPT1. Salt Lake City, Utah: US Department of Agriculture Forest Service, Remote Sensing Applications Center, 29 pp.

Landmann, T. (2003). Characterizing sub-pixel Landsat ETM+ fire severity on experimental fires in the Kruger National Park, South Africa. South African Journal of Science, 99, 357-360.

Lentile, L. B., Holden, Z. A., Smith, A. M. S., Falkowski, M. J., Hudak, A. T., Morgan, P., et al. (2006). Remote sensing techniques to assess active fire characteristics and post-fire effects. International Journal of Wildland Fire, $15,319-345$

Lewis, S. A., Wu, J. Q., \& Robichaud, P. R. (2006). Assessing burn severity and comparing soil water repellency, Hayman Fire, Colorado. Hydrological Processes, 20, 1-16.

Lutes, D. C., Keane, R. E., Caratti, J. F., Key, C. H., Benson, N. C., Sutherland, S., et al. (2006). FIREMON: Fire Effects Monitoring and Inventory System. Gen. Tech. Rep. RMRS-GTR-164-CD. Fort Collins, Colorado: US Department of Agriculture Forest Service, Rocky Mountain Research Station, 1 CD.

Miller, J. D., \& Yool, S. R. (2002). Mapping forest post-fire canopy consumption in several overstory types using Landsat TM and ETM data. Remote Sensing of Environment, 82, 481-496.

Moody, J. A., \& Martin, D. A. (2001). Initial hydrologic and geomorphic response following a wildfire in the Colorado Front Range. Earth Surface Processes and Landforms, 26, 1049-1070.

Moody, J. A., Smith, J. D., \& Ragan, B. W. (2005). Critical shear stress for erosion of cohesive soils subjected to temperatures typical of wildfires. Journal of Geophysical Research, 110(F1). doi:10.1029/2004JF000141.

Mundt, J. T., Glenn, N. F., Weber, K. T., Prather, T. S., Lass, L. W., \& Pettingill, J. (2005). Discrimination of hoary cress and determination of its detection limits via hyperspectral image processing and accuracy assessment techniques. Remote Sensing of Environment, 96, 509-517.

Orlemann, A., Saurer, M., Parsons, A., \& Jarvis, B. (2002). Rapid delivery of satellite imagery for burned area emergency response (BAER). Proceedings of the Ninth Biennial Forest Service Remote Sensing Applications Conference, San Diego, California, 8-12 April unpaginated CD-ROM.

Parsons, A. (2003). Burned area emergency rehabilitation (BAER) soil burnseverity definitions and mapping guidelines. RSAC-2003-RPT1. Salt Lake City, Utah: US Department of Agriculture Forest Service, Remote Sensing Applications Center, 9 pp.

Parsons, A., \& Orlemann, A. (2002). Mapping post-wildfire burn severity using remote sensing and GIS. 2002 ESRI International User Conference, 8-12 July 2002, San Diego, California, 9 pp.

Patterson, M. W., \& Yool, S. R. (1998). Mapping fire-induced vegetation mortality using Landsat Thematic Mapper data: A comparison of linear transformation techniques. Remote Sensing of Environment, 65, 132-142.

Roberts, D. A., Smith, M. O., \& Adams, J. B. (1993). Green vegetation, nonphotosynthetic vegetation and soils in AVIRIS data. Remote Sensing of Environment, 44, 255-269.

Robichaud, P. R. (2000). Fire effects on infiltration rates after prescribed fire in Northern Rocky Mountain forests, USA. Journal of Hydrology, 231-232, 220-229.

Robichaud, P., MacDonald, L., Freeouf, J., Neary, D., Martin, D., \& Ashmun, L. (2003). Postfire rehabilitation of the Hayman Fire. In R. T. Graham (Ed.), Hayman Fire case study analysis. Gen. Tech. Rep. RMRS-GTR-114 (pp. 293-313). Fort Collins, Colorado: US Department of Agriculture Forest Service, Rocky Mountain Research Station.

Romme, W. H., Veblen, T. T., Kaufmann, M. R., Sherriff, R., \& Regan, C. M. (2003). Ecological effects of the Hayman Fire part 1: Historical (Pre-1860) and Current (1860 to 2002) fire regimes. In R. T. Graham (Ed.), Hayman Fire case study analysis. Gen. Tech. Rep. RMRS-GTR-114 (pp. 181-195). Fort Collins, Colorado: US Department of Agriculture Forest Service, Rocky Mountain Research Station.

Roy, D. P., Boschetti, L., \& Trigg, S. N. (2006). Remote sensing of fire severity: Assessing the performance of the normalized burn ratio. IEEE Geoscience and Remote Sensing Letters, 3(1), 112-116. 
RSAC (2005). Remote Sensing Applications Center Burned Area Emergency Response (BAER) Imagery Support. Salt Lake City, Utah: US Department of Agriculture Forest Service, Remote Sensing Applications Center. Available online at http://www.fs.fed.us/eng/rsac/baer/

Ryan, K. C. (2002). Dynamic interactions between forest structure and fire behavior in boreal ecosystems. Silva Fennica, 36(1), 13-39.

Ryan, K. C., \& Noste, N. V. (1983). Evaluating prescribed fires. In J. E. Lotan, B. M. Kilgore, W. C. Fischer, \& R. W. Mutch (Eds.), Proceedings of the Symposium and Workshop on Wilderness Fire Gen. Tech. Rep. INT-182 (pp. 230-238). Ogden, Utah: US Department of Agriculture Forest Service, Intermountain Research Station.

SAS Insititute Inc. (1999). SAS/STAT User's Guide, Volume 1, Version 8.2. Cary, North Carolina: Statistical Analysis Systems (SAS) Institute Inc.

Sorbel, B. J., \& Allen, J. L. (2005). Space-based burn severity mapping in Alaska's national parks. In M. Shah (Ed.), Alaska Park Science, Vol. 4(1). (pp. 4-11). Anchorage, AK: US Department of Interior. National Park Service, Alaska Regional Office. http://burnseverity.cr.usgs.gov/pdfs/ Park_Science_Burn_Severity_Mapping_in_Alaska_NPS.pdf

Smith, M. O., Ustin, S. L., Adams, J. B., \& Gillespie, A. R. (1990). Vegetation in deserts: I. A regional measure of abundance from multi-spectral images. Remote Sensing of Environment, 31, 1-26.

Smith, A. M. S., Wooster, M. J., Drake, N. A., Dipotso, F. M., Falkowski, M. J., \& Hudak, A. T. (2005). Testing the potential of multi-spectral remote sensing for retrospectively estimating fire severity in African Savannahs. Remote Sensing of Environment, 97, 92-115.

Theseira, M. A., Thomas, G., Taylor, J. C., Gemmell, F., \& Varjo, J. (2003). Sensitivity of mixture modeling to end-member selection. International Journal of Remote Sensing, 24(13), 1559-1575.

Townshend, J. R. G., Huang, C., Kalluri, S. N. V., Defries, R. S., \& Liang, S. (2000). Beware of per-pixel characterization of land cover. International Journal of Remote Sensing, 21(4), 839-843.

Trigg, S., \& Flasse, S. (2000). Characterizing the spectral-temporal response of burned savannah using in situ spectroradiometry and infrared thermometry. International Journal of Remote Sensing, 21(16), 3161-3168.

Trigg, S., \& Flasse, S. (2001). An evaluation of different bi-spectral spaces for discriminating burned shrub-savannah. International Journal of Remote Sensing, 22, 2641-2647.

van Wagtendonk, J. W., Root, R. R., \& Key, C. H. (2004). Comparison of AVIRIS and Landsat ETM+ detection capabilities for burn severity. Remote Sensing of Environment, 92, 397-408.

Williams, A. P., \& Hunt, E. R. (2002). Estimation of leafy spurge cover from hyperspectral imagery using mixture tuned matched filtering. Remote Sensing of Environment, 82, 446-456. 